\title{
The Innovation Paradox: A Critical Review of the Literature on Action Learning and Innovation
}

\author{
Mike Pedler, Centre for Action Learning Facilitation \\ Cheryl Brook, University of Portsmouth Business School
}

\begin{abstract}
This is a literature review which aims to explore selective literatures in action learning and innovation in order to illuminate insights into the gap between innovation, engagement and implementation in practice. We conducted a search for articles in the action learning field with titles, keywords or abstracts which mentioned innovation, beginning with work by Revans which highlighted our central concern : the innovation paradox. Our investigation took in books, but was principally focused on journal articles. We then explored the innovation literature, with a particular emphasis in our search on titles, key words and abstracts which mentioned 'service innovation' and 'organisational learning'. In essence, our review suggests that paradox theory may be a useful way of thinking about the problem of the resistances to, and the failures of, innovation, and that action learning may offer up a useful space in which the innovation paradox might be worked upon. The study is limited to a review of the extant literature and offers no empirical evidence to support its conclusions. Further research could focus on such questions as why innovation remains so elusive, and how might the practice of critical action learning help to enhance innovative capacity and capability.
\end{abstract}

\section{Introduction}

The UK has a long-standing problem of low productivity; a "puzzle" to most economists including the Bank of England (Barnett et al 2014). The UK Government's Annual Report on Innovation argues that the economy is reliant on this ability, noting that innovation is a "key driver of UK growth and economic prosperity, accounting for up to 70 per cent of economic growth in the long term" (Department of Business, Innovation \& Skills 2014: 3). Some economists (Arrow 1962; Stiglitz \& Greenwald 2014) take the view that the nature of innovation in modern knowledge-based economies means that learning has a key role in increasing productivity. This means that the government should intervene to increase the rate and amount of learning in the economy: "creating a learning society should be one of the major objectives of economic policy" (2014:6). However, this aspiration has some way to go; the UK Government's Innovation Report states that although the UK, and especially the universities sector, performs well by international standards, only a "relatively small proportion of firms (are) engaged in innovative activity" (2014: 3).

One possible explanation for this puzzle is the gap between invention and implementation that Revans termed the Innovation Paradox (1971: 75) whereby: "any new or specialist solution .... has to be integrated back into the total system of the enterprise". This is a problem that cannot be addressed through "best practice" type approaches: "Every effort to resolve this innovation paradox must be almost entirely situational" (1971: 90). As Bourner points out, the key question to ask of an innovation in practice is not whether it works but "who can work it?" (2011: 122). Arguably then, the 
quality of innovation in an organisation must rest on the quality of employee engagement in that enterprise.

Kahn $(1990,694)$.sees employee engagement as a multi-faceted construct with clear links to job performance; and defines it as: "the harnessing of organization members' selves to their work roles; in engagement, people employee and express themselves physically, cognitively and emotionally during role performances". Similarly, Truss et al (2006) define employee engagement as simply a 'passion for work' that encompasses the three dimensions of engagement: physical, cognitive and emotional. As Rumbles and Rees (2013) point out, this definition of engagement means that the employee must be psychologically as well as physically present when occupying and performing an organizational role.

Action learning is an approach to engaging participants in learning from their attempts to improve things. It belongs to a family of action approaches to research and learning, in which knowledge is produced from, and also used in, action (Raelin: 1999). Whilst it is often conceived as a small group method for management and leadership development (Pedler, Burgoyne \& Brook 2005), Revans' ambition was to help with innovation and improvement in whole systems (1982: 280-286)

This paper will review some of the literatures of action learning and innovation. In the case of the huge extensive innovation literature, this will be highly selective and focus upon innovation as a learning process. Questions to be explored in this paper are:

- How does learning, and specifically action learning, stand in the current state of the debate on how to promote innovation via workforce engagement in an organisation or economy?

- How is innovation seen and conceptualised in the literature on action learning?

- What evidence exists to support the notion of "innovation capability" in a system or organisation?

- How can action learning help with the wicked problem of innovation?

A number of observations emerge from our analysis of the literatures of action learning and innovation, including:

- The apparent elusiveness of innovation in organisations, and the continuing question of what inhibits innovation and why;

- The apparent active resistance to innovation present in many organisations, which may be in part to do with risk aversion;

- The conclusion that action learning offers the space within which the innovation paradox can be worked upon.

\section{Innovation and Learning: evasion, resistance and paradox}

The literatures which form the principal focus of this paper consist firstly of literature which considers a wide range of learning processes which may be said to enable innovation. Secondly, the paper addresses literature which cites action learning as a potential and actual enabler of innovative 
practice, beginning with writings by Revans which touch on the subject of innovation as a learning process. Whilst the focus here is principally on enablers, there is a body of literature which addresses those factors which inhibit organisational learning which in turn has relevance to the problem of a failure to innovate (Vince and Saleem, 2004; Schilling and Kluge, 2009). Schilling and Kluge (2009) offer a theoretical foundation which builds on the key contribution made by Crossan et al (1999) and which is considered briefly below. This paper explores some of the key barriers to organisational learning in a systematic manner, including the barriers to 'intuiting'; in other words to the generation of new ideas (2009:343).

Schumpeter (1942) is an essential starting point for discussions on innovation, a topic in which interest has now grown to such an extent that it appears on the menu of technical and professional Journals in most professional fields including almost every Journal in Business and Management. Schumpeter gives innovation a central role in the dynamics of capitalism by twinning it with "creative destruction" as the driving force of economic development. Innovation is "the carrying out of new combinations" including:

(1) the introduction of a new good

(2) a new method of production

(3) the opening of a new market

(4) a new source of supply

(5) the development of a new form of industrial organization

Kanter (1984) re-conceptualizes innovation as a process of bringing new problem solving techniques into usage within organisations which makes a good fit with action learning as an approach 'cradled in the very task itself' (1998:5). As Garavan et al (1999) have observed, innovation comes from individuals, not organisations, thus innovation constitutes a degree of risk to both innovator and organization, 'with the result that it will only take place in organisations where the organizational culture empowers individuals and accepts risk taking' (1999: 174). Action learning from its inception was an approach Revans coupled with what he termed the risk imperative, in which the problems worked upon must 'carry with them significant risk of penalty for failure' (1998: 8). Kanter (1984) notes the relationship between culture, structure and the freedom to innovate, and this links with Pedler's (1996) observations concerning the readiness or otherwise of organisations to accept the idea of action learning. He remarks that one of the main contributions of action learning is the creation of a culture of enquiry and questioning - an essential aspect of the learning climate needed in the learning company (1996:24).

\section{Enabling innovation}

This section of the review focuses on innovation as a learning process which thus enables innovation to take place. Various processes are proposed as supporting innovation in organisations and economies, and these are briefly considered here. Organisational learning is commonly cited as enabling innovation (Cooke \& Morgan 1998; Aragon-Correa et al 2007; Chanal V 2004; HernandezEspallardo et al 2012; Jiménez-Jiménez \& Sanz-Valle 2011; Stiglitz \& Greenwald 2014). Organisational learning is a broad concept and can include more a range of specific factors that are 
cited as supporting innovation. The idea of Core Capabilities (Leonard-Barton 1992), which are particular corporate qualities comprising norms, values, skills, technical systems and managerial systems, acts as a family term for various organisational learning capabilities seen as supporting innovation.

These learning capabilities include "Innovation Capability", described by Olssen et al (2010:169) as 'the ability to continuously develop innovations as a response to a change in environment" and includes work procedures, organisational and technical learning and learning networks. Alternative formulations include the "Relational Capacity for Learning and Innovation" (Murphy et al's 2012) which includes the ability to build relations, the quality of power relations and the existence of various integration mechanisms, and "Relational Intelligence" (Hernandez-Espallardo et al, 2012) which emphasises the establishment of external relationships and the management of inter-firm learning processes.

According to Cooke \& Morgan (1998: 9) successful innovation depends upon a firm's "Associational Capacity": "that is, its capacity for forging cooperation between managers and workers within the firm, for securing cooperation between firms in the supply chain, and for crafting cooperative interfaces between firms and wider institutions." "Absorptive Capacity" (Cohen \& Levinthal 1990) describes "a firm's ability to recognize, assimilate, and exploit knowledge from within and without" (Cooke \& Morgan 1998:16), and depends upon the organisational learning processes through which firms internalise knowledge from the outside to meet commercial ends, and which in turn depend upon the establishment and management of the organisation's interface with its environment, and also on the cognitive variety of organisational members who receive and interpret the knowledge.

These various formulations of learning capabilities seem often to be constructed on common ground. Summarising a number of studies, Cooke \& Morgan (1998:29) report that theories of innovation and economic development often cite intangible factors such as trust, voice and loyalty as every bit as important as tangible factors like fixed investment. The notion of "Social Capital" denotes a capacity to share knowledge, especially tacit knowledge, which rests on a high degree of trust and commitment among members (Pedler \& Attwood 2011). The ability to share tacit knowledge through intensive social interaction is held to be the key to organizational knowledge-creation in Japanese firms (Nonaka 1994; Nonaka \& Takeuchi 1995). Processes of social interaction are underpinned by shared cognitive frameworks that facilitate the sharing of personal and context-dependent tacit knowledge.

Randhawa and Scerri (2015) offer a review of service innovation literature which reinforces the point that literature on this topic is significant, diverse and 'expanding into a cross disciplinary body of knowledge' (2015:27). This expansion has its roots in their observation that services have overtaken production and manufacturing as a dominant force in the world economy. Randhawa and Scerri's (2015) review covers a very wide range of service innovation literature which they organise into three broad themes: overview of service innovation, the dynamic and systemic process of service innovation and the management of service innovation. Widely recognised as an engine of economic progress, innovation evolved as a subject of academic study from the mid twentieth century onwards. Initially the interest was in technological change and product development. With the growth of services attention has shifted to innovation in the context of services over the last 20 years. 
The first theme is service innovation and its particular character. The requirement in many organisations is to deliver 'elevated service offerings' which leads to service innovation (Randhawa and Scerri, 2015; Agarwal and Selen, 2011). Innovation in services is 'an interplay of service concepts, service delivery systems, client interfaces and technologies (den Hartog 2000) but it also is concerned with the ways in which customers both view and use services. Services are characterised by intangibility, perishability, heterogeneity and interactivity (Randhawa and Scerri, 2015; Sampson, 2007). Thus a problem for organisations seeking sustainable competitive advantage is how to retain knowledge associated with service innovation and avoid 'leakage' to competitors, especially as service innovation is tested openly in the market, not in an R\&D department.

The literature points to the fact that whilst innovation in manufacturing is more product oriented and relies on technical expertise, service innovation relies more on 'cultural capabilities' (Ettlie and Rosenthal, 2012) and customer facing soft skills, especially communication skills. Randhawa and Scerri (2015) point to an apparent gap in the literature on the increasing role of technology in service innovation (Menor et al, 2002) and so there may be scope for exploring the role of virtual action learning in supporting innovation.

In terms of service design, there is some interest in the idea and practice of involving customers in the design of services - the co-creation of services - and the evaluation of existing service delivery with a view to exploring scope for improvement. Johnson et al (2000) have developed an interactive model that accounts for the iterative processes of new service development which provides more opportunities for the incorporation of feedback loops. The renal patient services action learning sets which included patients as set members may offer a useful example of service innovation through user engagement. Such collaborative approaches suggest that the old 'linear' value chain (Porter, 1985) may have given way to a 'hybrid' model which comprises a network of interested parties (stakeholders, customers, suppliers, partners etc). Randhawa and Scerri (2015: 35) cite Russo-Spena and Mele's (2012) process of five 'Co-s': co-ideation, co-valuation, co-design, co-test and co-launch, through which all these interested parties co-innovate.

Turning to the question of how innovation spreads, and the ways in which new ideas, ways of working and new knowledge get adopted Randhawa and Scerri (2015: 37) draw on two models: McGuire's (1989) hierarchy of effects and Prochaskas's (1992) stages of change model to demonstrate how innovation diffuses:

Stage 1: Knowledge stage - of skill required for effective innovation

Stage 2: Persuasion stage - contemplation of required new behaviour

Stage 3: Decision stage - preparedness to try

Stage 4 Implementation stage - action required for continued use of innovation, and

Stage 5 Confirmation stage - maintaining the benefits.

Linked to this is the question of managing organisational knowledge and learning for service innovation. Organisational learning is said to be achieved through learning-by-doing (Nonaka \& Toyama, 2005), experimentation (Thomke, 2003), knowledge sharing (Otto, 2012) codification of knowledge (Nonaka \& Takeuchi, 1995) and absorptive capacity (Cohen \& Levinthal, 1990) all of which 
is critical to knowledge creation 'which in turn drives innovation' (Randhawa and Scerri, 2015:39). Randhawa and Scerri (2015) go on to suggest that research focusing on the processes of organisational knowledge and learning for service innovation is relatively scarce. They also make the point that organisational culture as a driver of service innovation is being increasingly recognised in the literature. Culture impacts innovation and vice versa. Service innovation requires a culture which fosters collaboration and co-evolutionary learning mechanisms including customer involvement and this requirement for a collaborative culture is reminiscent of Pedler's (1996) development of the idea of organisational readiness for action learning for the approach to genuinely take root.

Schilling and Kluge's (2009) key paper on barriers to organisational learning makes particular mention of the barriers to 'intuiting' based on a careful review of a range of relevant literature. On the basis of their review, they suggest that a variety of what they term 'actional-personal, structuralorganisational and societal-environmental' barriers are in place against intuiting 'so that all forms of obstacles seem to play their part in preventing novel insights and innovative ideas' (2009:344). Amongst the many barriers identified the authors find lack of motivation of the innovator, restrictive, controlling management style, organisational blame culture, unclear criteria for success and the presence of implicit and immobile knowledge' (2009:343).

\section{Revans and innovation}

Action learning has been suggested as a medium by which actionable knowledge, which is to say knowledge which is implementable by the users whom it is intended to engage, can be co-created (Antonacopolou, 2009). Innovation is an essential assumption in Revans thinking about action earning. It is implicit in his calls for fresh thinking, fresh questions and questioning insight, and in his ideas of learning as equaling or exceeding the rate of change, and in the recognition of the need for unlearning and that new learning means the escape from old mindsets, or from the "idolization of past experience" (1982; 2011).

Various aspects of innovation can be identified in Revans' writings: his ecological injunction $-L \geq C$ holds that unless learning $(L)$ equals or exceeds the rate of change $(C)$ then any system, enterprise or society will fall behind and be overwhelmed by competitors:

"If the rate of change in the chemical industry is now a thousand times what it was a century ago, we may assert with confidence that the chemical industry must face problems of adjustment unknown to it's ancestors. Whole organizations, not only selected individuals within them, must learn to adjust. There must be collective as well as occasional learning, institutional and social as well as personal and individual development. Moreover, because change has become the most significant feature of our economy, the managerial process of absorbing it deserves no less to be understood that the technical advances of the particular industry being changed." (1971: xv/xvi).

This passage makes two fundamental points about Revans' position. First, although he does not dispute the role of investment and technological advances in innovation, it is learning, both individual and institutional, that is the critical factor. Secondly, in drawing attention to the "managerial process of absorbing" change, he is seeing innovation not as an event but as a practice. Revans' learning theory is based on the cycle of scientific method (2011: 14). Ideas remains hypothetical until tested in action, and learning happens through reflecting on the experiences of 
taking action. The action learning set of 6 or 8 peers is the crucible for forging this action and learning: "the cutting edge of the action learning programme (2011: 25).

Revans view of learning includes both the ideas of unlearning and collective or organisational learning: "Learning is not an acquisition of the new knowledge so much as a re-arrangement of the old. We try, by taking repeated action, to build, out of what we already know, those successive programmes of behaviour that enable us, with increasing accuracy, to predict their outcomes." (1971: 106). This, innovation and learning comes more from the re-configuration of old experiences than from the acquisition of new knowledge: and unlearning is especially important in this process, because new learning depends upon escaping from old mindsets and from the "the idolisation of past experience" (2011:42). This is well described by Mike Bett, then Personnel Director of GEC:

"Whatever may action learning may be adapted to the needs of GEC companies, the object will always be to encourage managers to examine the habits of mind they have acquired and become more receptive to new solutions to familiar management problems" ("It's opening our minds" (1977: 118) HERE

The collective learning process is seen as especially vital for innovation, although it is not well understood:

".... it is the change and growth process in the group, in the industrial community, in the company, and in our wider society that grants us final success. We are still far from understanding what this process of collective change and growth maybe, much less from knowing how individual managers may initiate and control it." (1971: Pp x/xi).

Revans' second key contribution is to identify innovation not as an event but as a practice, and with the practical doing of innovation, including the collective practice of organisational learning. An organisation's ability to innovate turns on the quality of its leadership and management:

"Again and again, the diagnoses of the problems turned upon the simple questions, "But what is this enterprise, in the final analysis, trying to do?" "Who, within it, really cares about what it does?" .... "What does the enterprise see as the key role of innovation and research, to do present things better or to replace present things with new?" "And when this question has found an answer, does anybody really want to act upon it?" (1971: 16).

For Revans, 'action' is always specific at a particular here and now:

" Action cannot be taken In general terms; it always was, is, and always will be dependent on its conditions and on those who take it." (1971:98)

Whilst technical innovations may be copied or duplicated, innovations in ways of working cannot be transplanted and have to be uniquely performed and realised. Innovations in supervision, management and leadership practices are unlikely to follow simply from examples of "best practice" or "evidence-based practice" \{Refs on eg the "Beacons" in Schools \& LG or "Share and Spread" in the NHS?]. Without seeking to re-invent the wheel itself, each practitioner has to re-invent the wheel of their own practice: 
"It is one thing to share new knowledge but another entirely to share a new practice. Even if a practitioner can make their innovation work in practice, what is the likelihood that it will work for others? In the context of practitioner-centred research (Bourner et al. 2000), we concluded that the key question to ask of an innovation in practice is not whether it works but who can work it?" Bourner T (2011) "Self-Managed Action Learning" in Pedler M (Ed) Action learning in practice 4th ed. p122

\section{The Innovation Paradox}

Revans' Innovation Paradox rest on the inherent risks of doing things differently. In Machiavelli's famous words from The Prince: "There is nothing more difficult to take in hand, more perilous to conduct, or more uncertain in its success, than to take the lead in the introduction of a new order of things." (1513). Revans freights his endorsement of this view with personal experience, making the "risk imperative" (2011: 6-9) an essential aspect of action learning:

" The pioneer of radical growth is therefore the person able and ready to pose discriminating questions in conditions of ignorance, risk and confusion... and to hold his ground in doing so." (1982: $699 / 700)$ and...

"It is, of course, true, as the history of action learning itself reveals, that all fundamental innovation, by whomsoever it is first advocated, is at once ridiculed and then opposed, and all participants must develop the ability to incorporate such rejection into their plans." (2011: 34).

To overcome the risks, Revans argues that the collaboration and support of close and trusted colleagues is essential. The action learning set: "the cutting edge of every action learning programme" (2011: 25) both enacts and symbolises the collaborative nature of innovation:

"In the risk-laden predicament of innovation each manager needs the support, not of those expert in yesterday's successes, but of their fellow managers going through the same tricky apprenticeship of facing tomorrow's confusion." (2011: 55).

"Early experience, among the colliery managers and the hospital administrations where the first consortia were set up so long ago, suggested that those in charge of a unit are much more likely to face the risks of innovation if several of them can be got together to stimulate each other to think afresh." (2011: 80)

Although we are arguably still far from a full understanding the processes of organisational learning and the problem of integrating individual and organisational learning, and Revans makes these key to the resolution of the "Innovation Paradox":

"any new or specialist solution found by the departmental management nominated to deal with the key problem has to be integrated back into the total system of the enterprise" (1971: 75).

"Experience of the projects seems to suggest that success in promoting change depends upon the resolution of an obvious paradox: action must be specific at a particular point by a particular individual, although its effects will be felt generally by all whose tasks intercept with that of the individual initiating the action. The successful change is that in which the effects of a highly specific 
actions are well integrated into more general practice, and it is in this integration that the quality of communications within the enterprise plays a decisive part." (1971 Footnote p27)

"Every effort to resolve this innovation paradox must be almost entirely situational." (1971: 90

The Innovation Paradox helps explain why so many organisation development or improvement schemes fail or only partially succeed. Revans "praxeology" or general theory of human action, which connects the individual actor with the wider, collective context via the three overlapping systems of alpha, beta \& gamma, is his attempts to understand and integrate individual and organisational learning (1971: 33-67). Success in resolving the Innovation Paradox depends greatly on the quality of management and leadership practices in any system, including top management support: "the higher management itself must become operationally involved, so as by their weight to press for the most far-reaching improvements" (1971: 176); at least one member of the top coalition needs to support the innovation. The quality of communication is also regarded as of central importance (1971: 33). Revans makes it clear that innovations need wider support and collaboration to succeed, and talks of the need to move outwards "from set to (the) learning community" of the whole enterprise via "supporting assemblies" and "key groups" made up of people who can influence and/or are affected by the change (2011: 37-8; 71-3).

This collaborative principle is in sharp contrast with the discourse of the individual "hero innovator" bequeathed us by 19th Century writers such as Samuel Smiles' (Self Help 1859) who extolled the great inventors and engineers as outstanding characters whose single-minded perseverance overcame all handicaps and rejections. Whilst this is a persistent cultural image, Revans notes that the adoption of new practices is not likely to be based on impersonal evidence or logic, but upon trust in the proposer:

"Experience of several hundred action learning programmes shows that most busy managers follow particular new lines of action, not so much because they are convinced by the logic behind them, but because of their personal belief in the other person advocating to them the innovation." (2011: $33 / 34)$.

\section{Since Revans}

A number of more recent writers have considered action learning as a means of bring about innovation. Using a detailed case study, Kuhn \& Marsick (2005) suggest that action learning can help trigger innovation in mature organisations which have become sclerotic in their thinking and may thus require the application of "fresh questions". Learmonth (2005) discusses the use of action learning as a tool for developing networks and building evidence-based practice in public health and comments on the way in which the set can help with the 'apparently rational' process of realizing evidence-based practice.

Olssen et al (2010) describe a three year project in a consortium of companies and university centers, each pursuing its own innovation project in medical technology, in which action learning provides a means of increasing "innovation capability". This concept is described as a company's ability to continuously develop innovations as a response to a change in environment. Components include work procedures, organisational and technical learning, learning networks and adaptability to new 
contextual environments. Wyton \& Payne (2014) describe a large scale project involving 96 managers action learning to develop lean management in a division of a multinational company. Many innovations are claimed, mostly improving nature, include: "22 separate activities ... started as a consequence of the wider intervention with an estimated average value of $£ 20,000$ to the business" (2014: 58).

In an interesting case of resistance to innovation, Dovey \& Rembach (2015) describe a "boutique" post-graduate programme in an Australian university, where all participants were involved via an action research process in the leadership of the programme. As a result of the resistance experienced from the host institution to this innovation, the focus is on the politics of innovation:

".......innovation is a notoriously difficult strategy to execute. Given its intention to transform the status quo, it is not surprising that in most organizations the rhetoric of innovation substitutes for its practice. To innovate successfully, the (usually powerful) interests that are vested in the status quo have to be addressed effectively. "(2015: 280)

Dovey \& Renbach suggest that one way to do this is via 'intrapreneurs' who are knowledgeable regarding the "management of the politics of innovation" which comprises both "the politics of resistance and the politics of persistence"(2015: 286). This idea seems to correspond with the notion of "tempered radicals" who both "want to rock the boat, and they want to stay in it" (Meyerson 2003: xi). Dovey \& Renbach are especially good at desribing the many forms of resistance expereinced including structural inertia, fear of creating precedents and fear of loss of financial control. The forms of persistence needed to overcome there include courage of convictions, collective energy, evidence of progress and learning and personal growth: "persistence is exercised not as a chore but as a manifestation of a life aligned to a meaningful mission" (2015: 289). And equally heroically, this role allows members the opportunity to be engaged in something perceived to be "greater than themselves" (2015: 289)

\section{Conclusion}

Innovation does not seem to be the straightforward process that may often be implied, and may be as much celebrated for its absence as for its presence. As noted at the outset, the UK (along with other advanced economies) has a long-standing problem of low productivity and whilst innovation is seen as a key driver of prosperity, most firms are not engaged in innovative activity. Innovation is commonly assumed to be something that is achieved by investing in research, education, R\&D and new technologies. But this applies more to new product innovation, upon which much of the literature is centred, rather than on the service or practice innovations that are equally vital in an advanced, "knowledge" economy. Our concern here is with innovation in professional, management and leadership practices, where "new kit" takes the form of people and their actions, both individual and collective. As Bourner (2011:122) notes, the question here is not so much the technical "Does this innovation work?" but "Who can make this innovation work?". And this question:

... "depends as much on the beliefs and values of the practitioners as it does on their technical ability. For this reason, those who wish to share an innovation need to be explicit about the beliefs and values that underpin it since only those who share those beliefs and values are likely to be able to make the new practice work well." 
Revans has thought deeply about the politics of innovation and his action learning is constructed so as to support "comrades in adversity" in overcoming the inertia and resistances to "fresh questions". And yet the adequacy of prescriptions such as supporting assemblies to achieve the integration of individual actions with wider organisational adoption that is required to resolve the "Innovation Paradox" may be questioned in the light of the many barriers, entrenched powers and shifting resistances described for example by Dovey \& Renbach (2015).

This wicked problem seems to urgently require further research. Firstly: why is innovation so often elusive? Despite the plethora of prescriptions for enabling innovation, why does it remain so stubbornly difficult? Garavan et al (1999) suggest that previous attempts at innovation influence present innovative capacities, and that 'history is crucial in the organisation's future development' (1999: 175), which perhaps links with some current thinking on unlearning. Brook et al (2016: 369) propose a significant role for unlearning in addressing "the wicked problems of organisational and social life", noting that whilst unlearning is often taken to be a sub-category of learning involving the discarding of obsolete knowledge to make way for the new, it has more radical implications via the notions of "critical unlearning" and "not-knowing".

In asking the question of why companies fail to innovate, Kalling (2007) suggests that the common reliance on organisational learning and knowledge acquisition and creation as enablers of innovation may mask organisational and institutional factors that have inhibiting effects. He concludes that, in practice and for various reasons, innovation is often a low priority for both line and senior managements. Because innovation involves risk for both innovator and organisation, an insufficient organisational readiness will stifle innovation and as well as action learning. Kalling also suggests other factors that may also impact negatively such as the capacities for effective team working and the preparedness to learn from and with each other.

Secondly, is the resistance to innovation active or passive or both? There would be great value in having more "thick" descriptions of the ways in which innovation fails or peters out. Revans' rhetoric includes a great deal about blockages to learning and "the idolisation of past experience" along with the (often baleful) attitudes of senior management and the ridicule which awaits the innovator, whilst Dovey \& Rembach's (2015) well documented case implies considerable activity in their experiences of resistance to innovation in Higher Education.

Thirdly, does paradox theory offer a useful way of thinking about the problem? Andriopoulos \& Lewis (2010) suggest that innovation is a process embedded, or perhaps mired, in paradoxes.

Achieving innovation requires the management of some contrasting and conflicting processes such as the needs to pursue both short-term survival and long-term sustainability. Handling such paradoxes requires in turn paradoxical approaches to managing or "ambidexterity" (2010: 104). Action learning might offer the space wherein the innovation paradox can be worked upon, but this may not be achieved through conventional action learning but rather through the form of critical action learning (Vince et al 2016). Such a formulation may involve unlearning, including the creative destruction of unhelpful knowledges, the admission of alternatives, including those neglected or suppressed, and openness to emergence (Brook et all 2016).

Finally, critical action learning allows for some questions which may point to a yet bigger paradox. If some of the critical questions likely to impact on those who can or cannot make innovations work include: 
- Who benefits from this innovation? And who loses?

- What will the new practices look like? Who can influence these emerging practices? What will be their impacts on jobs, freedom, power, privacy, autonomy?

- What is the function of the discourses of innovation? Whose interests are being served?

These questions apply to all innovations of course. But where practice or organising innovations are concerned they acquire a special significance, not least because, as Revans always pointed out, learning is a voluntary activity, but also because management and leadership practices carry moral, ethical and political considerations. In beginning his final book with the words: "Something is profoundly wrong with the way we live today." Tony Judt (2010: 1) quotes the 19th Century political theorist, Alexis de Tocqueville:

"I cannot help fearing that men may reach a point where they look on every new theory as a danger, every innovation as a toilsome trouble, every social advance as a first step towards revolution, and that they may absolutely refuse to move at all."

\section{References}

Andriopoulos, C. and Lewis, M. W. (2010). Managing Innovation Paradoxes: Ambidexterity lessons from leading product design companies. Long Range Planning 43(1): 104-122.

Arrow K (1962) "The Economic Implications of Learning by Doing" Review of Economic Studies 29: $155-173$

Aragon-Correa, Garcia-Morales \& Corzon-Puzo (2007). Leadership and organizational learning's role on innovation and performance: Lessons from Spain Industrial Marketing Management 36, 349-359

Barnett A, Batten S, Chiu A, Franklin J \& Sebastia-Barriel M (2014) "The UK Productivity Puzzle" Bank of England Quarterly Bulletin Q2 London

http://www.bankofengland.co.uk/publications/Documents/quarterlybulletin/2014/qb14q201.pdf

Brook C, Pedler M, Abbott C \& Burgoyne J (2016) "On stopping doing those things that are not getting us to where we want to be: Unlearning, wicked problems and critical action learning" Human Relations 2016, Vol. 69(2) 369-389

Bourner T (2011) "Self-Managed Action Learning" in Pedler M (Ed) Action learning in practice 4th Ed Farnham: Gower 113-123

Chanal V (2004),"Innovation management and organizational learning: a discursive approach", European Journal of Innovation Management, Vol. 7 (1) pp. 56 - 64

Cohen, M. and Levinthal, D. (1990), "Absorptive capacity: a new perspective on learning and innovation", Administrative Science Quarterly, Vol. 35 No. 1, pp. 128-52.

Cooke P \& Morgan K (1998) The Associational Economy: Firms, regions, and innovation Oxford: OUP 
Department of Business, Innovation \& Skills (2014) The Innovation Report 2014 London www.gov.uk/government/uploads/system/uploads/attachment_data/file/293635/bis-14-p188innovation-report-2014-revised.pdf

Dovey K \& Rembach M (2015) "Invisible practices, innovative outcomes: intrapreneurship within the academy" Action Learning: Research \& Practice 12(3) November 276-292

Garavan, T, Heraty, N \& Barnicle, B (1999) Human resource development literature: current issues, priorities and dilemmas. Journal of European Industrical Training. 23 (4/5) 169-179.

Hernandez-Espallardo M, Molina-Castillo F \& Rodriguez-Orejuela A (2012),"Learning processes, their impact on innovation performance and the moderating role of radicalness", European Journal of Innovation Management, Vol. 15 (1) pp. 77 - 98

Jiménez-Jiménez D \& Sanz-Valle R (2011) Innovation, organizational learning, and performance Jnl of Business Research 64 408-417

Judt T (2010) III Fares the Land New York: Allen Lane

Kanter, RM (1984) The Change Masters, London: Unwin.

Kahn, W. (1990) Psychological conditions of personal engagement and disengagement at work. Academy of Management Journal 33: 692-724

Kalling T (2007) "The lure of simplicity: learning perspectives on innovation", European Journal of Innovation Management, Vol. 10 (1) pp. 65 - 89

Leonard-Barton, D. (1992), "Core capabilities and core rigidities: a paradox in managing new product development", Strategic Management Journal, Vol. 13 No. 1, pp. 111-25.

Murphy M, Perrot F \& Rivera-Santos M (2012) New perspectives on learning and innovation in crosssector collaborations Jnl of Business Research 65 1700-1709

Nonaka, I. (1994), "A dynamic theory of organizational knowledge creation", Organization Science, Vol. 5 No. 1, pp. 14-37.

Nonaka, I \& Takeuchi, H (1995), The knowledge creating company: how Japanese companies create the dynamics of innovation, New York: Oxford University Press

Pedler, M., Burgoyne, J.G. and Brook, C. (2005) 'What has action learning learned to become?', Action Learning: Research \& Practice, 2 (1): 49-68.

Pedler M \& Attwood M (2011) How can Action learning contribute to social capital? Action Learning: Research \& Practice 8(1) pp 27-39

Shows dimensions of social capital esp new relationships and new ways of working- value of relational social capital. Olssen A, Wadell C, Odenrick P \& Norell Bergendahl M (2010) The action learning method for increasing innovation capability in organisations 7(2) pp 167-179.

Stiglitz J \& Greenwald B (2014) Creating a Learning Society: A New approach to Growth, Development, and Social Progress New York: Columbia University 2014, 
Raelin, J. (1999) 'Preface to a Special Issue "The Action Dimension in Management": Diverse approaches to research, teaching and development', Management Learning, 30 (2): 115-25.

Revans RW (1971) Developing Effective Managers New York: Praeger

Revans RW (1982) The Origins \& Growth of Action Learning Bromley UK: Charwell Bratt

Revans, R (2011) ABC of Action Learning Farnham: Gower.

Schilling, J and Kluge, A (2009) Barriers to organisational learning: an integration ofn theory and research. International Journal of Management Reviews. 11(3) 337-360.

Stiglitz J \& Greenwald B (2014) Creating a Learning Society: A New approach to Growth, Development, and Social Progress New York: Columbia University Press.

Vince, $R$ and Saleem, $T$ (2004). The impact of caution and blame on organisational learning. Management Learning, 35(2), 133-154.

Vince, R., Abbey, G. Bell, D. and Langenhan, M. (2016) 'Finding Critical Action Learning Through Paradox: The role of action learning in the suppression and stimulation of critical reflection', Working Paper, University of Bath, UK

Wyton \& Payne (2014) "Exploring the development of competence in Lean management through action learning groups: a study of the introduction of Lean to a facilities management function" Action Learning: Research \& Practice 11(1). pp 42-61 